FASST Soil Moisture, Soil Temperature: Original Versus New

Susan Frankenstein

April 2008 


\title{
FASST Soil Moisture, Soil Temperature: Original versus New
}

\author{
Susan Frankenstein \\ Cold Regions Research and Engineering Laboratory \\ US Army Engineer Research and Development Center \\ 72 Lyme Road \\ Hanover, New Hampshire 03755-1290
}

Final report

Approved for public release; distribution is unlimited.

\author{
Prepared for US Army Corps of Engineers \\ Washington, DC 20314-1000 \\ Under Work Unit 32664K
}




\begin{abstract}
This paper discusses only the differences between the original version of FASST (Frankenstein and Koenig 2004a, 2004b) and the new version. This report is intended as a supplement to the original model documentation. In its original incarnation, energy and mass transport associated with water vapor in the soil matrix were ignored. The author added these so that model usage could be expanded to include biological investigations yet still retain its initial focus of soil strength, and sensor performance inputs. Also ignored in the original version was water transport due to soil temperature gradients. In determining the new soil temperatures and moistures, the original model first achieved convergence in the temperature profile followed by the moisture profile at a given time step. The new version of FASST solves both of these sets of equations simultaneously. No changes have been made to the equations describing the canopy physical state except to allow for mixed precipitation.
\end{abstract}

DISCLAIMER: The contents of this report are not to be used for advertising, publication, or promotional purposes. Citation of trade names does not constitute an official endorsement or approval of the use of such commercial products. All product names and trademarks cited are the property of their respective owners. The findings of this report are not to be construed as an official Department of the Army position unless so designated by other authorized documents. 


\section{Contents}

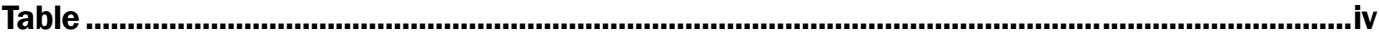

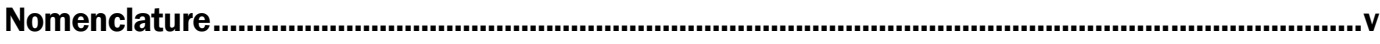

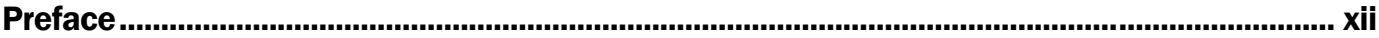

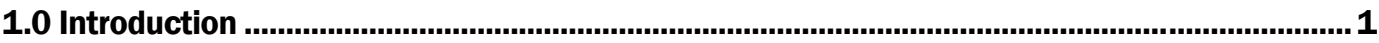

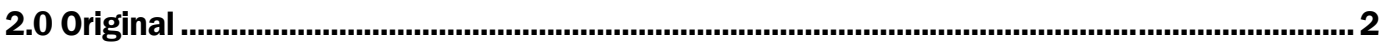

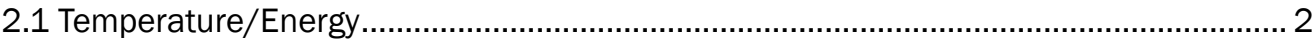

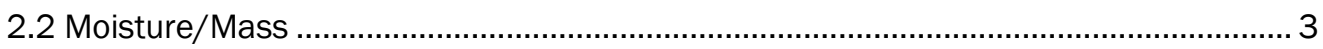

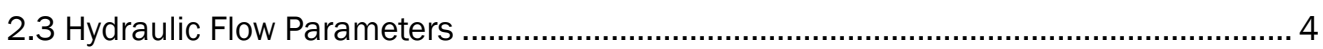

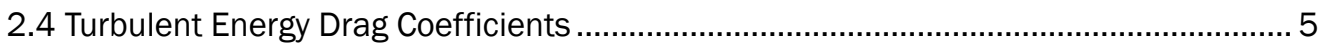

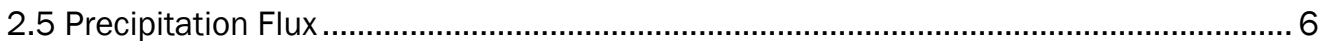

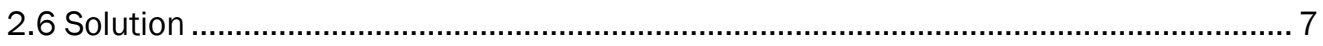

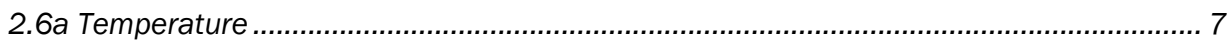

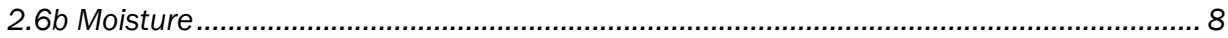

3.0 New

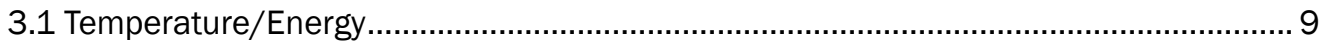

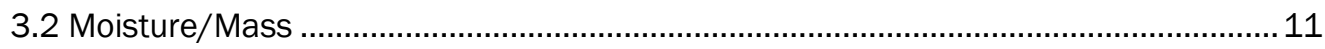

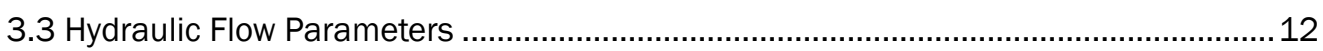

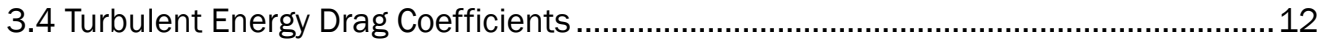

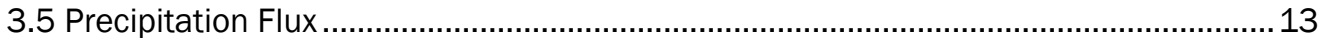

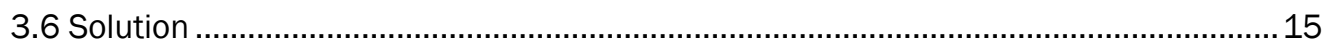

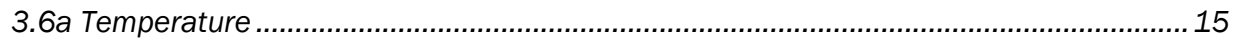

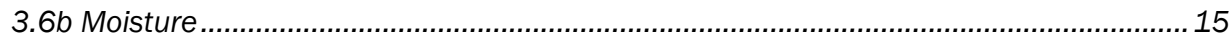

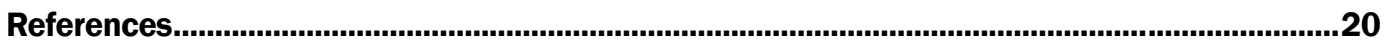

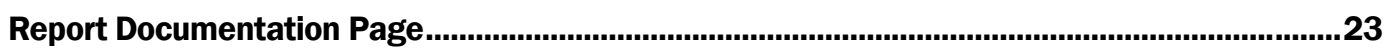




\section{Table}

Table 1. Physical properties of water, ice, air, and water vapor ...................................................... 10 


\section{Nomenclature}

$f \quad$ subscript indicating low foliage (shrubs, grass, crops, etc., vegetation) terms

$g \quad$ subscript indicating ground terms

$\alpha_{f}, \alpha_{g} \quad$ shortwave albedo ( $\left.0-1\right)$

$\alpha_{v G} \quad$ van Genuchten pressure head constant $\left(\mathrm{cm}^{-1}\right)$

$\alpha_{t, j} \quad$ numerical calculation constant

$\beta_{t, j} \quad$ numerical calculation constant

$\delta_{t, j} \quad$ numerical calculation constant

$\Delta t \quad$ time step (sec)

$\Delta z \quad$ node thickness $(m)$

$\varepsilon_{f}, \varepsilon_{g} \quad$ longwave emissivity (o-1)

$\varepsilon_{1} \quad$ calculation variable $\left(\varepsilon_{1}=\varepsilon_{f}+\varepsilon_{g}-\varepsilon_{f} \varepsilon_{g}\right)$

$\phi_{t, j} \quad$ numerical calculation constant $(K)$

$\gamma \quad$ soil water surface tension $\left(\mathrm{g} / \mathrm{s}^{2}\right)$

$$
\gamma=75.6-0.1425(T-273.15)-2.38 \times 10^{-4}(T-273.15)^{2}
$$

$\gamma_{d} \quad$ bulk dry density of soil $\left(\mathrm{kg} / \mathrm{m}^{3}\right)$

$\gamma_{p} \quad$ precipitation density $\left(\mathrm{kg} / \mathrm{m}^{3}\right)$

$\gamma_{t, j} \quad$ numerical calculation constant

$\gamma_{0} \quad$ soil water surface tension at $25{ }^{\circ} \mathrm{C}\left(71.89 \mathrm{~g} / \mathrm{s}^{2}\right)$

$\eta \quad$ mechanistic enhancement factor for vapor flow

$\Gamma_{e} \quad$ latent heat exchange stability correction factor

$\Gamma_{h} \quad$ sensible heat exchange stability correction factor 


\begin{tabular}{|c|c|}
\hline$\Gamma_{m}$ & momentum stability correction factor \\
\hline$\kappa$ & thermal conductivity $(\mathrm{W} / \mathrm{m} \cdot \mathrm{K})$ \\
\hline$\kappa_{a}$ & thermal conductivity of dry air $(\mathrm{W} / \mathrm{m} \cdot \mathrm{K})$ \\
\hline$\kappa_{i}$ & thermal conductivity of ice $(\mathrm{W} / \mathrm{m} \cdot \mathrm{K})$ \\
\hline$\kappa_{v}$ & thermal conductivity of water vapor $(\mathrm{W} / \mathrm{m} \cdot \mathrm{K})$ \\
\hline$\kappa_{v e g}$ & vegetation thermal conductivity $\left(\kappa_{v e g}=0.38 \mathrm{~W} / \mathrm{m} \cdot \mathrm{K}\right)$ \\
\hline$\kappa_{w}$ & thermal conductivity of water $(\mathrm{W} / \mathrm{m} \cdot \mathrm{K})$ \\
\hline$v_{v}$ & vertical rate of water vapor flow $(\mathrm{m} / \mathrm{s})$ \\
\hline$v_{w}$ & vertical rate of water flow $(\mathrm{m} / \mathrm{s})$ \\
\hline$\mu_{j, i}$ & numerical calculation constant \\
\hline$\theta_{i}$ & volumetric ice content $\left(\mathrm{cm}^{3} / \mathrm{cm}^{3}\right)$ \\
\hline$\theta_{\max }$ & maximum soil moisture content $\left(\mathrm{m}^{3} / \mathrm{m}^{3}\right)$ \\
\hline$\theta_{r}$ & residual soil moisture content $\left(\mathrm{m}^{3} / \mathrm{m}^{3}\right)$ \\
\hline$\theta_{v}$ & volumetric vapor content $\left(\mathrm{cm}^{3} / \mathrm{cm}^{3}\right)$ \\
\hline$\theta_{w}$ & volumetric water content $\left(\mathrm{cm}^{3} / \mathrm{cm}^{3}\right)$ \\
\hline$\rho_{a}$ & air density at the instrument height $\left(\mathrm{kg} / \mathrm{m}^{3}\right)$ \\
\hline$\rho_{a f}$ & density of air in the atmosphere/foliage interface \\
\hline & $\rho_{a f}=0.5\left(\rho_{a}+\rho_{f}\right)\left(\mathrm{kg} / \mathrm{m}^{3}\right)$ \\
\hline$\rho_{a g}$ & density of air at the foliage/ground interface $\left(\mathrm{kg} / \mathrm{m}^{3}\right)$ \\
\hline$\rho_{f}$ & air density in the foliage $\left(\mathrm{kg} / \mathrm{m}^{3}\right)$ \\
\hline$\rho_{i}$ & density of ice $\left(\mathrm{kg} / \mathrm{m}^{3}\right)$ \\
\hline$\rho_{v}$ & density of water vapor $\left(\mathrm{kg} / \mathrm{m}^{3}\right)$ \\
\hline$\rho_{v s}$ & saturated water vapor density $\left(\mathrm{kg} / \mathrm{m}^{3}\right)$ \\
\hline$\rho_{w}$ & density of water $\left(\mathrm{kg} / \mathrm{m}^{3}\right)$ \\
\hline$\sigma$ & Stefan-Boltzman constant $\left(5.699 \mathrm{e}-08 \mathrm{~W} / \mathrm{m}^{2} \cdot \mathrm{K}^{4}\right)$ \\
\hline
\end{tabular}




\begin{tabular}{|c|c|}
\hline$\sigma_{f}$ & foliage fractional coverage \\
\hline$\Psi$ & pressure head $(m)$ \\
\hline$c_{p}$ & specific heat of the soil $(\mathrm{J} / \mathrm{kg} \cdot \mathrm{K})$ \\
\hline$c_{p, a}$ & specific heat of air $(\mathrm{J} / \mathrm{kg} \cdot \mathrm{K})$ \\
\hline$c_{p, i}$ & specific heat of ice $\left(-13.3+7.80 T_{a} \mathrm{~J} / \mathrm{kg} \cdot \mathrm{K}\right)$ \\
\hline$c_{p, p}$ & precipitation specific heat $(J / \mathrm{kg} \cdot \mathrm{K})$ \\
\hline$c_{p, s}$ & specific heat of dry soil $(\mathrm{J} / \mathrm{kg} \cdot \mathrm{K})$ \\
\hline$c_{p, v}$ & specific heat of water vapor $(\mathrm{J} / \mathrm{kg} \cdot \mathrm{K})$ \\
\hline$c_{p, v e g}$ & specific heat of vegetation $\left(3500 \sigma_{f} \mathrm{~J} / \mathrm{kg} \cdot \mathrm{K}\right)$ \\
\hline$c_{p, w}$ & specific heat of water $(J / \mathrm{kg} \cdot \mathrm{K})$ \\
\hline$C_{e}$ & empirical coefficient associated with $\Gamma_{e}$ \\
\hline$C_{e}^{g}$ & bulk transfer coefficient for latent heat near the ground \\
\hline$C_{e n}^{g}$ & $\begin{array}{l}\text { bulk transfer coefficient near the ground for near-neutral } \\
\text { conditions }\end{array}$ \\
\hline$C_{f}$ & bulk transfer coefficient for turbulent heat in the foliage \\
\hline$C_{h}$ & empirical coefficient associated with $\Gamma_{h}$ \\
\hline$C_{h}^{g}$ & bulk transfer coefficient for sensible heat near the ground \\
\hline$C_{h n}^{f}$ & $\begin{array}{l}\text { bulk transfer coefficient for latent heat at the top of the foliage } \\
\text { for near-neutral conditions } C_{h n}^{f}=\left[k / \ln \left(\frac{Z_{a}-Z_{d}}{z_{0}^{f}}\right)\right]^{2}\end{array}$ \\
\hline$C_{h n}^{g}$ & $\begin{array}{l}\text { bulk transfer coefficient for sensible heat near the ground for } \\
\text { near-neutral conditions }\end{array}$ \\
\hline$C_{m}$ & empirical coefficient associated with $\Gamma_{m}$ \\
\hline$C_{n g}^{0}$ & $\begin{array}{l}\text { bulk transfer coefficient for momentum near the ground for } \\
\text { near-neutral conditions }\end{array}$ \\
\hline
\end{tabular}


$C_{r} \quad$ condensation rate

D molecular diffusivity of water vapor in air $\left(\mathrm{m}^{2} / \mathrm{s}\right)$

$D_{h} \quad$ molecular thermal diffusion coefficient $\left(\mathrm{m}^{2} / \mathrm{s}\right)$

$D_{r}, D_{s} \quad$ vegetation dripped rain, snow $(\mathrm{m} / \mathrm{s})$

$D_{v} \quad$ molecular diffusion coefficient of water vapor $\left(\mathrm{m}^{2} / \mathrm{s}\right)$

$e_{o} \quad$ windless sensible heat correction factor $\left(2.0 \mathrm{~W} / \mathrm{m}^{2}\right)$

E evaporation rate $(\mathrm{m} / \mathrm{s})$

$f_{1}, f_{2}, f_{3} \quad$ variables used to calculate stomatal resistance

$F_{f} \quad$ sum of energy terms at the atmosphere/foliage interface $\left(\mathrm{W} / \mathrm{m}^{2}\right)$

$g \quad$ gravity $\left(9.81 \mathrm{~m}^{2} / \mathrm{s}\right)$

$h \quad$ total head $(m)\left[h=z-\Psi=z-P_{a} / \rho_{w} g\right]$

$h_{\text {pond }} \quad$ head due to water collecting on the surface $(m)$

$h_{i, m e l t} \quad$ head due to melting ice $(m)$

$h_{s, \text { melt }} \quad$ head due to melting snow $(m)$

$H_{f} \quad$ sensible heat at the atmosphere/foliage interface $\left(W / m^{2}\right)$

$$
H_{f}=\left(e_{0}+1.1 L A I \rho_{a f} c_{p, a} C_{f} W_{a f}\right)\left(T_{a f}-T_{f}\right)
$$

$H_{g} \quad$ sensible heat at the foliage/ground interface $\left(\mathrm{W} / \mathrm{m}^{2}\right)$

$$
H_{g}=\left(e_{0}+\rho_{a g} c_{p, a} C_{h}^{g} W_{a f}\right)\left(T_{a f}-T_{g}\right)
$$

$H_{R} \quad$ relative humidity of the soil $(\mathrm{o}-1)$

$I_{\text {ir }}^{\downarrow} \quad$ total incoming infrared radiation $\left(\mathrm{W} / \mathrm{m}^{2}\right)$

$I_{r}, I_{s} \quad$ vegetation intercepted rain, snow $(\mathrm{m} / \mathrm{s})$

$I_{s}^{\downarrow} \quad$ total incoming solar radiation

$k \quad$ von Karmen's constant $(k=0.4)$

$k_{t h} \quad$ soil thermal diffusivity $\left(k_{t h}=\kappa / c_{p} m^{2} / s\right)$

$K_{l h} \quad$ pressure-driven hydraulic conductivity $(\mathrm{m} / \mathrm{s})$

$K_{l T} \quad$ temperature-driven hydraulic conductivity $\left(\mathrm{m}^{2} / K \cdot \mathrm{s}\right)$ 
$K_{\text {sat }} \quad$ saturated hydraulic conductivity $(\mathrm{m} / \mathrm{s})$

$K_{v h} \quad$ pressure-driven vapor conductivity $(\mathrm{m} / \mathrm{s})$

$K_{v T} \quad$ temperature-driven vapor conductivity $\left(m^{2} / K \cdot s\right)$

$l \quad$ latent heat $(\mathrm{J} / \mathrm{kg})$

$l_{\text {fus }} \quad$ latent heat of fusion $(\mathrm{J} / \mathrm{kg})$

$l_{s u b} \quad$ latent heat of sublimation $(2.838 \mathrm{e} 06 \mathrm{~J} / \mathrm{kg})$

$l_{w} \quad$ latent heat of vaporization $(\mathrm{J} / \mathrm{kg})$

$L_{f} \quad$ latent heat at the atmosphere/foliage interface $\left(\mathrm{W} / \mathrm{m}^{2}\right)$

$$
L_{f}=\operatorname{LAI} \rho_{a f} C_{f} I W_{a f} r^{\prime \prime}\left(q_{a f}-q_{f, \text { sat }}\right)
$$

$L_{g} \quad$ latent heat at the foliage/ground interface $\left(W / \mathrm{m}^{2}\right)$

$$
L_{g}=C_{e}^{g} l W_{a f} \rho_{a g}\left(q_{a f}-q_{g}\right)
$$

LAI foliage Leaf Area Index $\left(\mathrm{m}^{2} / \mathrm{m}^{2}\right)$

$$
L A I=L A I_{\text {min }}+\left(1.0-0.0016\left[298.0-T_{g}\right]^{2}\right)\left[L A I_{\text {max }}-L A I_{\text {min }}\right]
$$

$L A I_{\min } \quad$ minimum foliage Leaf Area Index $\left(\mathrm{m}^{2} / \mathrm{m}^{2}\right)$

$L A I_{\max }$ maximum foliage Leaf Area Index $\left(\mathrm{m}^{2} / \mathrm{m}^{2}\right)$

$m_{c} \quad$ soil clay fraction $(0-1)$

$m_{v G} \quad$ van Genuchten constant $\left(m_{v G}=1-1 / n_{v G}\right)$

$M \quad$ molecular weight of water $(0.018015 \mathrm{~kg} / \mathrm{mol})$

$n \quad$ soil porosity $(0-1)$

$n_{v G} \quad$ van Genuchten constant

$P_{a} \quad$ pressure $(\mathrm{Pa})$

$P_{f} \quad$ precipitation heat at the atmosphere/foliage interface $\left(\mathrm{W} / \mathrm{m}^{2}\right)$

$$
P_{f}=-\gamma_{p}[1.0-\exp \{-0.5(L A I+S A I)\}] P_{r} c_{p} T_{p}
$$

$P_{g} \quad$ precipitation heat at the foliage/ground interface $\left(\mathrm{W} / \mathrm{m}^{2}\right)$

$$
P_{g}=-\gamma_{p}\left(P_{r}-\text { Interception }+ \text { Drip }\right) c_{p, p} T_{p}(m / s)
$$

$P_{r} \quad$ precipitation rate $(\mathrm{m} / \mathrm{s})$

$q_{a} \quad$ mixing ratio of air above the foliage 
$q_{a f} \quad$ mixing ratio of the air at the foliage interface

$$
q_{a f}=\frac{\left[\left(1-\sigma_{f}\right) q_{a}+\sigma_{f}\left(0.3 q_{a}+0.6 q_{f, s a} r^{\prime \prime}+0.1 q_{g, s a t} H_{R}\right)\right]}{1-\sigma_{f}\left[0.6\left(1-r^{\prime \prime}\right)+0.1\left(1-H_{R}\right)\right]}
$$

$q_{f} \quad$ mixing ratio of air at the top of the foliage

$q_{g} \quad$ mixing ratio of air at the ground surface

$q_{f, \text { sat }} \quad$ saturated foliage mixing ratio

$q_{g, s a t} \quad$ saturated ground mixing ratio

$q_{\text {top }} \quad$ surface water flux (m/s)

$r_{a} \quad$ atmospheric resistance to water vapor diffusion $r_{a}=1 / C_{f} W_{a f}$ $(s / m)$

$r_{c e} \quad$ turbulent Prandtl number $\left(r_{c e}=0.71\right)$

$r_{c h} \quad$ turbulent Schmidt number $\left(r_{c h}=0.63\right)$

$r_{s} \quad$ stomatal resistance to vapor diffusion $r_{s}=\frac{r_{s, \min }}{L A I} f_{1} f_{2} f_{3}(\mathrm{~s} / \mathrm{m})$

$r_{s, \min } \quad$ minimum stomatal resistance to vapor diffusion $(\mathrm{s} / \mathrm{m})$

$r^{\prime \prime} \quad$ foliage surface wetness factor $r^{\prime \prime}=r_{a}\left(r_{a}+r_{s}\right)^{-1}$

$R \quad$ universal gas constant for air $(8.314 \mathrm{~J} / \mathrm{mol} \cdot \mathrm{K})$

$R_{i b} \quad$ bulk Richardson number

SAI Stem area index

$t \quad$ time $(s)$

$T \quad$ temperature $(K)$

$T_{a} \quad$ air temperature $(K)$

$T_{a f} \quad$ air temperature in the foliage

$$
T_{a f}=\left(1-\sigma_{f}\right) T_{a}+\sigma_{f}\left(0.3 T_{a}+0.6 T_{f}+0.1 T_{g}\right)(K)
$$

$T_{f}, T_{g} \quad$ foliage, ground surface temperature $(K)$

$T_{p} \quad$ precipitation temperature (K)

$u_{*} \quad$ friction velocity $(\mathrm{m} / \mathrm{s})$ 


\begin{tabular}{|c|c|}
\hline $\mathrm{U}_{\mathrm{p}}$ & mass precipitation flux $\left(\mathrm{kg} / \mathrm{m}^{2} \cdot \mathrm{s}\right)$ \\
\hline $\mathrm{V}_{\mathrm{v}}$ & vapor flow rate $(\mathrm{m} / \mathrm{s})$ \\
\hline$V_{w}$ & water flow rate $(\mathrm{m} / \mathrm{s})$ \\
\hline $\mathrm{w}$ & relative soil moisture \\
\hline $\mathrm{W}$ & wind speed at the instrument height $Z_{a}(\mathrm{~m} / \mathrm{s})$ \\
\hline $\mathrm{W}_{\mathrm{af}}$ & $\begin{array}{l}\text { wind speed at the air/ foliage interface } \\
W_{a f}=0.83 \sigma_{f} W^{\prime} \sqrt{C_{h n}^{f}}+\left(1-\sigma_{f}\right) W^{\prime}(\mathrm{m} / \mathrm{s})\end{array}$ \\
\hline$W^{\prime}$ & adjusted wind speed $\left(W^{\prime}=2.0 \mathrm{~m} / \mathrm{s}\right.$ if $\mathrm{W}$ is below $2.0 \mathrm{~m} / \mathrm{s}$ ) \\
\hline $\mathrm{z}$ & depth (m) \\
\hline$z_{o}^{f}$ & foliage roughness length (m) \\
\hline$z_{o}^{g}$ & ground roughness length $(\mathrm{m})$ \\
\hline$z_{o}^{h}$ & sensible heat ground roughness length $(\mathrm{m})$ \\
\hline$z_{o}^{q}$ & latent heat ground roughness length (m) \\
\hline$Z_{a}$ & shelter/instrument height for air temperature (m) \\
\hline$Z_{d}$ & zero displacement height $Z_{d}=0.701 Z_{f}^{0.975}(\mathrm{~m})$ \\
\hline$Z_{f}$ & vegetation height (m) \\
\hline$Z_{r h}$ & $\begin{array}{l}\text { height above the ground of the relative humidity measurement } \\
\text { (m) }\end{array}$ \\
\hline$Z_{u}$ & height of the measured wind speed (m) \\
\hline
\end{tabular}




\section{Preface}

This technical report was prepared by Susan Frankenstein, Research Physical Scientist, Terrestrial and Cryospheric Sciences Branch, US Army Engineer Research and Development Center (ERDC), Cold Regions Research and Engineering Laboratory (CRREL), Hanover, New Hampshire.

The author thanks Geoff Koenig and Connie Scott for proofreading the report and "test driving" the model. The author also thanks Greg Fall at NOAA's NOHRSC for helping to debug the new version.

This report was prepared under the general supervision of Dr. Mark L. Moran, Chief, Terrestrial and Cryospheric Sciences Branch; Dr. Justin B. Berman, Chief, Research and Engineering Division, CRREL; and Dr. Robert E. Davis, Director, CRREL.

At the time this work was performed, Colonel Richard B. Jenkins was Commander and Executive Director of ERDC. Dr. James R. Houston was Director. 


\subsection{Introduction}

This paper discusses only the differences between the original version of FASST (Frankenstein and Koenig 2004a, 2004b) and the new version. This report is intended as a supplement to the original model documentation. In its original incarnation, energy and mass transport associated with water vapor in the soil matrix were ignored. I added these so that model usage could be expanded to include biological investigations yet still retain its initial focus of soil strength, and sensor performance inputs. Also ignored in the original version was water transport due to soil temperature gradients. In determining the new soil temperatures and moistures, the original model first achieved convergence in the temperature profile followed by the moisture profile at a given time step. The new version of FASST solves both of these sets of equations simultaneously. No changes have been made to the equations describing the canopy physical state except to allow for mixed precipitation.

To begin, section 2.0 provides a brief synopsis of the original FASST governing equations and solution procedures that are different in the new version. Readers desiring more details should refer to Frankenstein and Koenig (2004a, 2004b). Section 3.0 contains the new version of the equations and solution procedures. A complete list of all parameters used can be found in the beginning of this report. 


\subsection{Original}

\subsection{Temperature/Energy}

The temperature gradient in a non-uniform soil layer can be described by the one dimensional heat flow equation

$$
\frac{\partial T}{\partial t}-\frac{l_{\text {fus }}}{c_{p}} \frac{\rho_{i}}{\rho_{w}} \frac{\partial \theta_{i}}{\partial t}=\frac{\partial}{\partial z}\left(\frac{\kappa}{c_{p}} \frac{\partial T}{\partial z}\right)-v_{w} \frac{c_{p, w}}{c_{p}} \frac{\partial T}{\partial z}
$$

where $T$ is the temperature $(K), t$ is time $(s), \kappa$ is the thermal conductivity $(\mathrm{W} / \mathrm{m} \cdot \mathrm{K}), c_{p, w}$ is the specific heat of water $(\mathrm{J} / \mathrm{kg} \cdot \mathrm{K}), \mathrm{c}_{p}$ is the specific heat of the soil $(\mathrm{J} / \mathrm{kg} \cdot \mathrm{K}), v_{w}$ is the vertical rate of water flow $(\mathrm{m} / \mathrm{s}), l_{\text {fus }}$ is the latent heat of fusion $(\mathrm{J} / \mathrm{kg}), \theta_{i}$ is the volumetric ice content $\left(\mathrm{cm}^{3} / \mathrm{cm}^{3}\right), \rho_{i}$ is the density of ice $\left(\mathrm{kg} / \mathrm{m}^{3}\right), \rho_{w}$ is the density of water $\left(\mathrm{kg} / \mathrm{m}^{3}\right)$, and $z$ is depth $(m)$ measured positive downward from the surface. The second term on the left-hand side of equation (2.1) represents heat lost/gained due to ice formation/melting and the terms on the right-hand side incorporate temperature changes due to vertical heat conduction and water flow, respectively.

If low vegetation is present, the atmosphere/foliage energy exchange is given as

$$
F_{f}=0=\sigma_{f}\left[I_{s}^{\downarrow}\left(1-\alpha_{f}\right)+\varepsilon_{f} I_{i r}^{\downarrow}-\varepsilon_{f} \sigma T_{f}^{4}-P_{f}\right]+\frac{\sigma_{f} \varepsilon_{f} \varepsilon_{g} \sigma}{\varepsilon_{1}}\left(T_{g}^{4}-T_{f}^{4}\right)+H_{f}+L_{f}
$$

$T_{f}$ is the foliage temperature (K), $T_{g}$ is the ground temperature $(K), \varepsilon_{g}$ is the ground emissivity, $\sigma$ is Stefan-Boltzman constant (5.699e-08 $\left.W / m^{2} \cdot K^{4}\right), I_{s}^{\downarrow}$ and $I_{\text {ir }}^{\downarrow}$ are the total incoming solar and infrared radiation $\left(W / m^{2}\right), H_{f}, L_{f}$, and $P_{f}$ are the sensible, latent, and precipitation heat fluxes at the foliage surface, respectively $\left(W / m^{2}\right)$, and $\varepsilon_{1}=\varepsilon_{f}+\varepsilon_{g}-\varepsilon_{f} \varepsilon_{g}$. The foliage fractional coverage $\sigma_{f}$, shortwave albedo $\alpha_{f}$, and emissivity $\varepsilon_{f}$ are functions of the vegetation type (high, medium, or low) and season (winter, spring, summer, and fall).

The energy flux exchange at the foliage/ground interface as 


$$
\begin{aligned}
F\left(T_{g}\right)=0= & \left(1-\sigma_{f}\right)\left[I_{s}^{\downarrow}\left(1-\alpha_{g}\right)+\varepsilon_{g} I_{i r}^{\downarrow}-\varepsilon_{g} \sigma T_{g}^{4}\right]-P_{g}-\frac{\sigma_{f} \varepsilon_{f} \varepsilon_{g} \sigma}{\varepsilon_{1}}\left(T_{g}^{4}-T_{f}^{4}\right) \\
& +H_{g}+L_{g}+\kappa \frac{\partial T_{g}}{\partial z}+l_{f u s} \frac{\rho_{i}}{\rho_{w}} \frac{\partial \theta_{i}}{\partial t} \Delta z-v_{w} c_{p, w} T_{g}
\end{aligned}
$$

where $\left(1-\sigma_{f}\right)$ represents the radiant fluxes not intercepted by the vegetation, $\alpha_{g}$ is the shortwave albedo of the ground, and $H_{g}, L_{g}$, and $P_{g}$ are the sensible, latent, and precipitation heat fluxes at the ground surface, respectively $\left(W / m^{2}\right)$, and $\Delta z(\mathrm{~m})$ is the thickness of the top node. Both $\alpha_{g}$ and $\varepsilon_{g}$ are a function of the soil type and range from 0.23 to 0.40 and 0.92 to 0.97 , respectively. The third term in the second row of equation (2.3) takes care of heat conduction to/from the surface by the underlying ground, depending on the temperature gradient. This is followed by the heat released/absorbed by the soil as the soil moisture melts/freezes. Finally, the last term represents heat that is advected away from/towards the surface as a result of the vertical movement of moisture.

The first term in equations (2.2) and (2.3) represent the amount of solar, or shortwave radiation, absorbed by the surface. The second term is the absorbed incoming longwave radiation while the third term is the emitted longwave radiation. The sensible and latent heat fluxes together are called the turbulent heat fluxes and have non-zero values in the presence of wind. The precipitation heat represents the energy needed to cool or heat any snow or rain that falls on the surface. The term after the precipitation heat flux represents the radiative exchange between the foliage and ground surfaces. In equations (2.2) and (2.3), heat that is transferred to the surface is considered positive.

\subsection{Moisture/Mass}

The flow of water $\left(v_{w}\right)$ through a porous media is governed by Darcy's Law, which states that

$$
v_{w}=K_{l h} \frac{\partial h}{\partial z}=-K_{l h}\left(-1+\frac{\partial \Psi}{\partial z}\right)
$$

where $K_{l h}(\mathrm{~m} / \mathrm{s})$ is the pressure-driven hydraulic conductivity and $h(\mathrm{~m})$ the total head equals the elevation head, or depth $(z)$, minus the pressure 
head ( $\Psi$ ), i.e., $h=z-\Psi=z-P_{a} / \rho_{w} g, P_{\mathrm{a}}(P a)$ is pressure, $\rho_{w}\left(\mathrm{~kg} / \mathrm{m}^{3}\right)$ is the density of water, and $g\left(9.81 \mathrm{~m}^{2} / \mathrm{s}\right)$ is gravity. For unsaturated soil, $\Psi<0$.

Also governing the flow of moisture through a soil is the conservation of mass, which states that the time rate of change of the moisture content in a given volume equals the net gain/loss of fluid in the volume, i.e.,

$$
\frac{\partial \theta_{w}}{\partial t}=-\frac{\partial v_{w}}{\partial z}-\frac{\rho_{i}}{\rho_{w}} \frac{\partial \theta_{i}}{\partial t}+\text { sources }- \text { losses }
$$

where $\theta_{w}\left(\mathrm{~cm}^{3} / \mathrm{cm}^{3}\right)$ is the volumetric moisture content. Equation (2.5) assumes that changes with respect to time in the soil porosity and water density are negligible compared to changes in the soil moisture and total head. The source and loss terms in this equation account for occurrences such as runoff and plant root uptake.

Equation (2.5) is subject to the following flow boundary conditions at the surface and at the bottom of the soil column

$$
\begin{array}{cc}
q_{\text {top }}=-E+C_{r}+P_{r}+\left(h_{\text {pond }}+h_{i, \text { melt }}+h_{s, \text { melt }}\right) / \Delta t & @ \mathrm{z}=0 \\
q_{\text {bot }}=K_{l h} \sin (\text { slope }) & @ \mathrm{z}=\mathrm{z}_{\text {bot }}
\end{array}
$$

where $E(\mathrm{~m} / \mathrm{s})$ is the evaporation rate, $C_{r}(\mathrm{~m} / \mathrm{s})$ is the condensation rate, $P_{r}(\mathrm{~m} / \mathrm{s})$ is the rate of precipitation, $h_{p o n d}(m)$ is the head due to water collecting on the surface, and $h_{i, m e l t}(\mathrm{~m})$ and $h_{s, m e l t}(\mathrm{~m})$ are the heads due to melting ice and snow, respectively, and $\Delta t(\mathrm{sec})$ is the time step. If the ground is sloped, no water accumulates and any water that falls on the surface, but does not infiltrate, becomes runoff.

\subsection{Hydraulic Flow Parameters}

The pressure-driven flow parameters are unchanged between the original and new versions of FASST. Since the temperature-controlled equivalent (see section 3.3) are related, I include them here for reference purposes. The relationship between volumetric moisture content and pressure head is highly nonlinear. As in the original version of FASST, following the work of van Genuchten (1980) 


$$
\theta_{w}=\theta_{r}+\frac{\theta_{\max }-\theta_{r}}{\left(1+\left|\alpha_{v G} \Psi\right|^{n_{v G}}\right)^{m_{v G}}}
$$

where $\theta_{r}$ is the residual volumetric water content, $\theta_{\max }$ is the maximum volumetric water content, $\alpha_{v G}\left(\mathrm{~cm}^{-1}\right)$ is a constant related to the reciprocal of the bubbling pressure head, $n_{v G}$ is a constant dependent on the distribution of pores, and $m_{v G}=1-1 / n_{v G}$.

The pressure-driven hydraulic conductivity, $K_{l h}$, is modified from the original version of FASST to take into account the decrease in flow under freezing conditions and is given as (van Genuchten 1980, Niu and Yang 2006)

$$
K_{l h}=K_{s a t}\left(1+8 \theta_{i}\right)^{2} w^{0.5}\left[1-\left(1-w^{1 / m_{v G}}\right)^{m_{v G}}\right]^{2} \quad w=\frac{\theta_{w}-\theta_{r}}{\theta_{\max }-\theta_{r}} .
$$

where $K_{\text {sat }}(\mathrm{m} / \mathrm{s})$ is the saturated hydraulic conductivity.

\subsection{Turbulent Energy Drag Coefficients}

The bulk transfer coefficient for sensible heat $C_{h}^{g}$ (Deardorff 1978) is calculated using the bulk transfer coefficient near the ground $C_{h n}^{g}$ (Koenig 1994) and at the atmosphere/foliage interface $C_{h n}^{f}$ (Balick et al. 1981) for nearneutral stability plus a sensible heat exchange stability correction factor $\Gamma_{h}$

$$
\begin{gathered}
C_{h}^{g}=\Gamma_{h}\left[\left(1-\sigma_{f}\right) C_{h n}^{g}+\sigma_{f} C_{h n}^{f}\right] \\
C_{h n}^{g}=\frac{\left[\frac{k}{\ln \left(Z_{a} / z_{o}^{g}\right)}\right]^{2}}{\left[r_{c h}+\frac{\ln \left(Z_{a} / Z_{u}\right)}{\ln \left(Z_{a} / z_{o}^{g}\right)}\right]} .
\end{gathered}
$$

The ground roughness length $z_{o}^{g}(m)$ is equal to $0.001 m$ for all soil types and $0.0006 m$ for snow. Since $Z_{a}(m)$, the height of the measured air temperature, equals $Z_{u}(m)$, the height of the measured wind speed, $C_{h n}^{g}$ reduces to 


$$
C_{h n}^{g}=\frac{\left[\frac{k}{\ln \left(Z_{a} / z_{o}^{g}\right)}\right]^{2}}{r_{c h}}
$$

where the turbulent Schmidt number $r_{c h}$ is hardwired in the code as 0.63 for all soil types, as is $k$, von Karmen's constant (0.4). The term $\Gamma_{h}$ in equation (2.9) accounts for non-neutral conditions and is defined as

$$
\begin{gathered}
\Gamma_{h}=\left\{\begin{array}{cc}
\frac{1.0}{\left(1.0-16.0 R_{i b}\right)^{0.5}} & R_{i b}<0.0 \\
1.0 & R_{i b}=0.0 \\
\frac{1.0}{1.0-5.0 R_{i b}} & 0.0<R_{i b}<0.2
\end{array}\right. \\
R_{i b}=\frac{2 g Z_{a}\left(T_{a f}-T_{g}\right)}{\left(T_{a f}+T_{g}\right) W_{a f}^{2}}
\end{gathered}
$$

where $R_{i b}$ is the bulk Richardson number. Similarly for the latent heat, $\Gamma_{e}=\Gamma_{h}$ and $C_{e n}^{g}$ follows the development for $C_{h n}^{g}$ with $Z_{a}$ being replaced with $Z_{r h}(m)$, the height above the ground of the relative humidity measurement, $r_{c h}$ with $r_{c e}$ the turbulent Prandtl number (0.71, hardwired in the code).

\subsection{Precipitation Flux}

In the original version of FASST, no mixed precipitation was allowed. Thus, for a bare surface it was defined as

$$
\begin{gathered}
P_{g}=U_{p} c_{p, p} T_{p} \\
U_{p}=-\gamma_{p} \cdot \text { fallrate }
\end{gathered}
$$

with $T_{p}$ the precipitation temperature defined as the air wet-bulb temperature, $c_{p, p}$ as either the specific heat of water, $c_{p, w}(4217.7 \mathrm{~J} / \mathrm{kg} \cdot \mathrm{K})$ or ice, $c_{p, i}$ $\left(-13.3+7.80 T_{a} \mathrm{~J} / \mathrm{kg} \cdot \mathrm{K}\right)$ depending on $T_{p}, U_{p}$ the mass precipitation flux $\left(\mathrm{kg} / \mathrm{m}^{2} \cdot \mathrm{s}\right)$, and $\gamma_{p}$ the precipitation density $\left(\mathrm{kg} / \mathrm{m}^{3}\right)$. The fallrate is in $(\mathrm{m} / \mathrm{s})$. 


\subsection{Solution}

Since the solutions to the temperature and moisture balances are discussed in detail in Frankenstein and Koenig (2004a, 2004b), I present only enough material so that comparisons can be made with the current procedures.

\section{6a Temperature}

Equation (2.1) is solved using a modified second-order Crank-Nicholson approach. Following the technique presented in Hornbeck (1975), equation (2.1) is rewritten as

$$
\begin{gathered}
\frac{T_{t+1, j}-T_{t, j}}{\Delta t}-\frac{l_{\text {fus }}}{c_{p}} \frac{\rho_{i}}{\rho_{w}} \frac{\left(\Delta \theta_{i}\right)_{t, j}}{\Delta t}=\left[\frac{k_{t t_{t, j+1}}-k_{t h_{t, j}}}{\Delta z}\right]\left[\frac{T_{t, j+1}-T_{t, j}}{\Delta z}\right]+ \\
\frac{k_{t h_{t, j}}}{2}\left[\frac{T_{t+1, j+1}-2 T_{t+1, j}+T_{t+1, j-1}}{(\Delta z)^{2}}+\frac{T_{t, j+1}-2 T_{t, j}+T_{t, j-1}}{(\Delta z)^{2}}\right] \\
-\frac{c_{p, w}}{c_{p_{j, i}}} v_{w: t, j}\left[\frac{T_{t, j+1}-T_{t, j}}{\Delta z}\right]
\end{gathered}
$$

where $k_{t h}=\kappa / c_{p}$ and the subscripts $t$ and $j$ represent time and depth, respectively. Combining like terms and rearranging so that all terms involving $T_{j+1}$ are on the left-hand side of the equation, equation (2.13) becomes

$$
\begin{gathered}
T_{t+1, j-1}+\gamma_{t, j} T_{t+1, j}+T_{t+1, j+1}= \\
-T_{t, j-1}+T_{t, j}\left(\beta_{t, j}+\alpha_{t, j}-\delta_{t, j}\right)+T_{t, j+1}\left(1-\beta_{t, j}+\delta_{t, j}\right)+\mu_{t, j} \equiv \phi_{t, j}
\end{gathered}
$$

where

$$
\begin{gathered}
\alpha_{t, j}=-2\left(\frac{(\Delta z)^{2}}{k_{t h_{t, j}}(\Delta t)}\right), \quad \gamma_{t, j}=\alpha_{t, j}-2, \quad \beta_{t, j}=2\left(\frac{k_{t t_{t, j+1}}}{k_{t h_{t, j}}}\right), \\
\delta_{t, j}=2 v_{w_{t, j}}\left(\frac{c_{p, w}}{c_{p_{t, j}}} \frac{\Delta z}{k_{t t_{t, j}}}\right), \quad \mu_{t, j}=\alpha_{t, j} \frac{l_{f u s}}{c_{p}} \frac{\rho_{i}}{\rho_{w}}\left(\Delta \theta_{i}\right)_{t, j} .
\end{gathered}
$$

For more detail see Frankenstein and Koenig (2004a). 
In the original version of FASST, the soil surface and foliage temperatures were solved for first. In order to solve equations (2.2) and (2.3), we (Frankenstein and Koenig 2004a) assumed that

$$
\begin{gathered}
T_{g}^{4}=\left(T_{g}\right)_{t-1}^{4}+4\left(T_{g}\right)_{t-1}^{3}\left[T_{g}-\left(T_{g}\right)_{t-1}\right] \\
q_{g, s a t}=q_{g, \text { sat }}\left(\left(T_{g}\right)_{t-1}\right)+\left.\frac{\partial q_{g, s a t}}{\partial T_{g}}\right|_{T_{g}=\left(T_{g}\right)_{t-1}}\left[T_{g}-\left(T_{g}\right)_{t-1}\right]
\end{gathered}
$$

where the subscript " $t-1$ " indicates the values of $T_{g}$ at the previous time step. $T_{f}^{4}$ and $q_{f \text {,sat }}$ are also represented by equation (2.16), substituting the subscript $g$ with $f$. The above substitutions allow the linearization of equations (2.2) and (2.3), which can then be solved simultaneously for $T_{f}$ and $T_{g}$. The final equations are thus (Frankenstein and Koenig 2004b)

$$
\begin{gathered}
c_{1}^{f}+c_{2}^{f} T_{g}+c_{3}^{f} T_{f}=0 ; \\
c_{1}^{g}+c_{2}^{g} T_{g}+c_{3}^{g} T_{f}=0 .
\end{gathered}
$$

\section{6b Moisture}

Equation (2.5) is solved numerically using an explicit scheme such that

$$
\frac{\theta_{w_{t+1, j}}-\theta_{w_{t, j}}}{\Delta t}=-\left[\frac{\left(v_{w}\right)_{t+1, j+1}-\left(v_{w}\right)_{t+1, j}}{\Delta z_{j}}\right]+\operatorname{sources}(j)-\operatorname{losses}(j)
$$

where

$$
\begin{aligned}
& \left(v_{w}\right)_{j}=\left(K_{l h}\right)_{j-1 / 2}\left[\frac{h_{j}-h_{j-1}}{z_{j}-z_{j-1}}\right] \\
& \left(v_{w}\right)_{j+1}=\left(K_{l h}\right)_{j+1 / 2}\left[\frac{h_{j+1}-h_{j}}{z_{j+1}-z_{j}}\right]
\end{aligned} .
$$

$h_{j}=z_{j}-\Psi_{j}$ and $\Delta z_{j}=\left(z_{j+1}-z_{j-1}\right) / 2$. The change in soil moisture content due to changes in the ice content, i.e., freezing/thawing, is incorporated into the source and sink terms. In Equation (2.5) it is the second term on the right-hand side. Reexpressing $\theta_{w}$ in terms of $\psi$ using equation (2.7), equation (2.18) is solved for $\psi$ using a Newton-Raphson technique. 


\subsection{New}

\subsection{Temperature/Energy}

Equation (2.1) has been modified to include temperature changes due to vapor flow. It is now

$$
\begin{gathered}
\frac{\partial c_{p} T}{\partial t}-l_{\text {fus }} \rho_{i} \frac{\partial \theta_{i}}{\partial t}+l_{w} \rho_{w} \frac{\partial \theta_{v}}{\partial t}=\frac{\partial}{\partial z}\left(\kappa \frac{\partial T}{\partial z}-v_{w} c_{p, w} T-v_{v} c_{p, v}(T-273.15)-l_{w} \rho_{w} v_{v}\right) \\
+c_{p, w} \rho_{w}(\text { sources - losses }) T
\end{gathered}
$$

where $l_{w}$ is the latent heat of vaporization $(\mathrm{J} / \mathrm{kg}), \theta_{v}$ is the volumetric water vapor content $\left(\mathrm{cm}^{3} / \mathrm{cm}^{3}\right), c_{p, v}$ is the specific heat of water vapor $(\mathrm{J} / \mathrm{kg} \cdot \mathrm{K})$, and $v_{v}$ is the vertical rate of water vapor flow $(\mathrm{m} / \mathrm{s})$. Another change from the original formulation is that $z(m)$ is now measured positive upwards from sea level.

The calculation of the specific heat, $c_{p}$, is slightly different than before due to the incorporation of water vapor into the soil matrix. The original equation was

$$
c_{p}=(1-n) \gamma_{d} c_{p, s}+\theta_{w} \rho_{w} c_{p, w}+\left(n-\left[\theta_{w}+\theta_{i}\right]\right) \rho_{a} c_{p, a}+\theta_{i} \rho_{i} c_{p, i} .
$$

It is now

$$
c_{p}=(1-n) \gamma_{d} c_{p, s}+\theta_{w} \rho_{w} c_{p, w}+\left(n-\left[\theta_{w}+\theta_{i}+\theta_{v}\right]\right) \rho_{a} c_{p, a}+\theta_{i} \rho_{i} c_{p, i}+\theta_{v} \rho_{v} c_{p, v} .
$$

See the list of variables at the beginning of the report for a description of all of the parameters. While the calculation of the thermal conductivity, $\kappa$, is the same as in the original version of FASST, the calculation of the individual components is different. Comparison of the original and new values of the thermal conductivity, specific heat, and density for water, air, ice, and water vapor are listed in Table 1. Unlike in the original version of FASST where we assumed that the specific heat and thermal conductivity of vegetation were negligible, I now assume that they are $c_{p, v e g}=3500$ $\mathrm{J} / \mathrm{kg} \cdot \mathrm{K}$ and $\kappa_{\text {veg }}=0.38 \mathrm{~W} / \mathrm{m} \cdot \mathrm{K}$ (Moore and Fisch 1986). 
Table 1. Physical properties of water, ice, air, and water vapor.

\begin{tabular}{|c|c|c|}
\hline Variable & Old & New \\
\hline $\begin{array}{c}c_{p, w} \\
T\left({ }^{\circ} \mathrm{C}\right) \\
(J / k g \cdot K)\end{array}$ & 4217.7 & $\begin{array}{l}\qquad-10^{-6} T^{5}+10^{-4} \mathrm{~T}^{4}-6 \times 10^{-3} T_{3}+10^{-1} T^{2}-2.9 T+4216.9 \\
\text { Hillel (1998) } \\
4216.9 \leq \mathrm{c}_{\mathrm{p}, \mathrm{w}} \leq 31500.0\end{array}$ \\
\hline $\begin{array}{c}c_{p, a} \\
T\left({ }^{\circ} \mathrm{C}\right) \\
(J / k g \cdot K)\end{array}$ & 1005.6 & 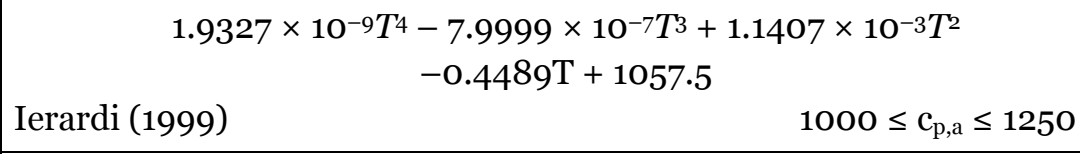 \\
\hline $\begin{array}{c}c_{p, i} \\
(J / k g \cdot K)\end{array}$ & $-13.3+7.80 T_{a}$ & $-13.3+7.80 T_{\mathrm{a}}$ \\
\hline $\begin{array}{c}c_{p, v} \\
(J / k g \cdot K)\end{array}$ & & $\begin{array}{c}2.3888 \times 10^{-8} T^{4}-6.5129 \times 10^{-5} T^{3}+6.6178 \times 10^{-2} T^{2} \\
\\
\quad-2.9086 \times 10^{1} T+6625.5 \\
\text { Ierardi (1999) } \quad 2000 \leq c_{p, v} \leq 3260\end{array}$ \\
\hline $\begin{array}{c}\rho_{w} \\
\left(\mathrm{~kg} / \mathrm{m}^{3}\right)\end{array}$ & 1000.0 & $\begin{array}{cc} & -3.0 \times 10^{-7} T^{4}+7.0 \times 10^{-5} T^{3}-9.92 \times 10^{-3} T^{2} \\
& +8.666 \times 10^{-2} T+999.81 \\
\text { Hillel (1998) } & 962 \leq \rho_{\mathrm{w}} \leq 1000\end{array}$ \\
\hline $\begin{array}{c}\rho_{a} \\
\left(\mathrm{~kg} / \mathrm{m}^{3}\right)\end{array}$ & $3.48 \times 10^{-3}\left(P_{a} / T_{a}\right)$ & $360.77819 T^{-1.00336}$ \\
\hline $\begin{array}{c}\rho_{i} \\
T\left({ }^{\circ} \mathrm{C}\right) \\
\left(\mathrm{kg} / \mathrm{m}^{3}\right)\end{array}$ & 916.5 & $\begin{array}{c}-2.0 \times 10^{-10} T^{6}-7.0 \times 10^{-8} T^{5}-1.0 \times 10^{-5} T^{4} \\
-7.0 \times 10^{-4} T^{3}-2.37 \times 10^{-2} T^{2}-4.36 \times 10^{-1} T^{3}+916.2 \\
\text { Engineering ToolBox (2005) } \\
916.2 \leq \rho_{\mathrm{i}} \leq 925.7\end{array}$ \\
\hline $\begin{array}{c}\rho_{v} \\
\left(\mathrm{~kg} / \mathrm{m}^{3}\right)\end{array}$ & & 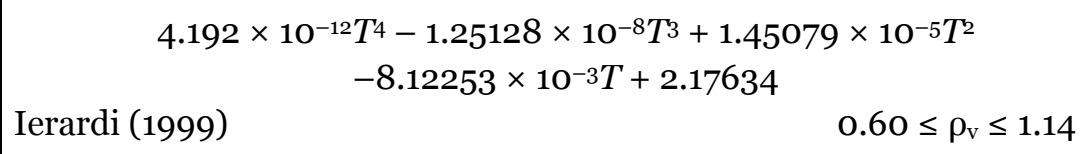 \\
\hline $\begin{array}{c}\kappa_{w} \\
(W / m \cdot K)\end{array}$ & $1.8 \times 10^{-3} \mathrm{~T}-0.0787$ & $1.8 \times 10^{-3} T-0.0787$ \\
\hline $\begin{array}{c}\kappa_{a} \\
(W / m \cdot K)\end{array}$ & & $\begin{aligned} & 1.5207 \times 10^{-11} T^{3}- 4.8574 \times 10^{-8} T^{2}+1.0184 \times 10^{-4} T \\
&-3.9333 \times 10^{-4} \\
& \text { Ierardi (1999) } \quad 0.0159 \leq \kappa_{\mathrm{a}} \leq 0.1000\end{aligned}$ \\
\hline $\begin{array}{c}\kappa_{i} \\
(W / m \cdot K)\end{array}$ & $488.19 T^{-1}+0.4685$ & $\begin{array}{cc}4.0 \times 10^{-7} T^{3}+1.0 \times 10^{-4} T^{2}-6.9 \times 10^{-3} T+2.2174 \\
\text { Engineering ToolBox }(2005) & 2.2174 \leq \kappa_{\mathrm{i}} \leq 3.4800\end{array}$ \\
\hline $\begin{array}{c}\kappa_{v} \\
(W / m \cdot K)\end{array}$ & & $\begin{aligned} 8.3154 \times 10^{-5 T}-7.4556 & \times 10^{-3} \\
& 0.00695 \leq \kappa_{\mathrm{v}} \leq 0.02360\end{aligned}$ \\
\hline
\end{tabular}

The new surface boundary conditions at the soil and vegetation surfaces are 


$$
\begin{aligned}
F_{f}= & =\sigma_{f}\left[I_{s}^{\downarrow}\left(1-\alpha_{f}\right)+\varepsilon_{f} I_{i r}^{\downarrow}-\varepsilon_{f} \sigma T_{f}^{4}-P_{f}\right]+\frac{\sigma_{f} \varepsilon_{f} \varepsilon_{g} \sigma}{\varepsilon_{1}}\left(T_{g}^{4}-T_{f}^{4}\right) \\
& +H_{f}+L_{f}+\sigma_{f} \kappa_{\text {veg }} \frac{\partial T_{f}}{\partial z} . \\
F\left(T_{g}\right)= & 0=\left(1-\sigma_{f}\right)\left[I_{s}^{\downarrow}\left(1-\alpha_{g}\right)+\varepsilon_{g} I_{i r}^{\downarrow}-\varepsilon_{g} \sigma T_{g}^{4}\right]-P_{g}-\frac{\sigma_{f} \varepsilon_{f} \varepsilon_{g} \sigma}{\varepsilon_{1}}\left(T_{g}^{4}-T_{f}^{4}\right) \\
& +H_{g}+L_{g}+l_{\text {fus }} \frac{\rho_{i}}{\rho_{w}} \frac{\partial \theta_{i}}{\partial t} \Delta z-l_{w} \rho_{w} \frac{\partial \theta_{v}}{\partial t}+\kappa \frac{\partial T_{g}}{\partial z}-\left(v_{w} c_{p}+v_{v} c_{p, v}\right)\left(T_{g}-273.15\right) \\
& -l_{w} \rho_{w} v_{v}+c_{p, w} \rho_{w}(\text { sources -losses }) T_{g} .
\end{aligned}
$$

Unlike in the original version of FASST where the bottom temperature was allowed to float, I assume a constant deep-earth heat flux for the bottom boundary condition of $75 \mathrm{~mW} / \mathrm{m}^{2}$.

\subsection{Moisture/Mass}

The water flow rate $\left(v_{w}\right)$ is now

$$
v_{w}=-K_{l h} \frac{\partial h}{\partial z}-K_{l T} \frac{\partial T}{\partial z}=-K_{l h}\left(1+\frac{\partial \Psi}{\partial z}\right)-K_{l T} \frac{\partial T}{\partial z} .
$$

where $K_{l T}$ is the temperature-dependent hydraulic gradient $\left(m^{2} / K \cdot s\right)$. The new moisture governing equation takes into account water flow due to temperature gradients, unlike the old version, which considered only flow due to gravity and pressure gradients. As with the temperature governing equations, vapor fluxes are also now accounted for. The new mass balance equations is

$$
\frac{\partial \theta_{w}}{\partial t}+\frac{\partial \theta_{v}}{\partial t}+\frac{\rho_{i}}{\rho_{w}} \frac{\partial \theta_{i}}{\partial t}=\frac{\partial}{\partial z}\left[K_{l h}-\frac{\partial \Psi}{\partial z}\left(K_{l h}+K_{v h}\right)+\frac{\partial T}{\partial z}\left(K_{l T}+K_{v T}\right)\right]+\text { sources - losses }
$$

where $K_{v T}$ is the temperature-dependent vapor gradient $\left(\mathrm{m}^{2} / K \cdot s\right)$, and $K_{v h}$ is the pressure-dependent vapor conductivity $(\mathrm{m} / \mathrm{s})$. The surface moisture boundary condition remains unchanged from the original version of FASST. 
Differences between equations (2.4) and (3.6) can be explained by the change in the vertical reference ( $z$ positive downward from the surface previously versus $z$ positive upward from sea level currently) and the inclusion of temperature gradient flow.

\subsection{Hydraulic Flow Parameters}

The temperature-dependent hydraulic gradient, $K_{l T}$, is given as (Hansson et al. 2004, Noborio et al. 1996)

$$
K_{l T}=K_{l h}\left(7 \Psi \frac{1}{\gamma_{o}} \frac{d \gamma}{d T}\right) .
$$

$\gamma=75.6-0.1425(T-273.15)-2.38 \times 10^{-4}(T-273.15)^{2}$ is the soil water surface tension $\left(\mathrm{g} / \mathrm{s}^{2}\right), \gamma_{o}=\gamma\left(25{ }^{\circ} \mathrm{C}\right)=71.89 \mathrm{~g} / \mathrm{s}^{2}$, and $K_{l h}$, the pressure-driven hydraulic conductivity, is defined in equation (2.8).

The water vapor flow rate $\left(v_{v}\right)$ is given by (Fayer, 2000)

$$
v_{v}=-K_{v h} \frac{\partial \Psi}{\partial z}-K_{v T} \frac{\partial T}{\partial z}
$$

where (Fayer 2000, Noborio et al. 1996, Nassar and Horton 1989)

$$
\begin{array}{cc}
K_{v h}=\frac{D \rho_{v s} M g}{\rho_{w} R T} H_{R} & D=0.66\left[n-\left(\theta_{w}+\theta_{i}\right)\right]\left[2.12 \times 10^{-5}\left(\frac{T}{273.15}\right)^{2}\right] \\
K_{v T}=\frac{D \eta H_{R}}{\rho_{w}} \frac{d \rho_{v s}}{d T} & \eta=9.5+6 \theta_{w}-8.5 \exp \left\{-\left[\left(1+2.6 m_{c}^{-1 / 2}\right) \theta_{w}\right]^{4}\right\} \\
H_{R}=\exp \left[-\frac{\Psi M g}{R T}\right] .
\end{array}
$$

$D$ is the molecular diffusivity of water vapor in air $\left(\mathrm{m}^{2} / \mathrm{s}\right), n$ is the porosity, $\eta$ is the mechanistic enhancement factor, $m_{c}$ is the clay fraction, $H_{R}$ is the soil relative humidity, $M$ is the molecular weight of water (0.018015 $\mathrm{kg} / \mathrm{mol}), R$ is the universal gas constant $(8.314 \mathrm{~J} / \mathrm{mol} \cdot \mathrm{K})$, and $\rho_{v \mathrm{~s}}$ is the saturated water vapor density $\left(\mathrm{kg} / \mathrm{m}^{3}\right)$. 


\subsection{Turbulent Energy Drag Coefficients}

An effort was made to move away from a more empirical formulation of the turbulent energy terms and instead to base them on the more widely accepted Monin-Obukhov similarity theory. Unfortunately, this requires iterating for a solution, which is numerically cost-prohibitive. In order to avoid this, I adopted the method of Mascart et al. (1995) and Louis (1979). The bulk transfer coefficients $C_{h n}^{g}$ and $C_{e n}^{g}$ are now defined as

$$
\begin{gathered}
C_{h n}^{g}=\frac{k^{2} / 0.74}{\ln \left(Z_{u} / z_{0}^{g}\right) \ln \left(Z_{u} / z_{0}^{h}\right)} \\
C_{e n}^{g}=\frac{k^{2} / 0.74}{\ln \left(Z_{u} / z_{0}^{g}\right) \ln \left(Z_{u} / z_{0}^{q}\right)}
\end{gathered}
$$

where $z_{o}^{h}(m)$ is the sensible heat roughness length and $z_{o}^{q}(m)$ is the moisture roughness length and all other terms are described in Section 2.3. The roughness lengths are calculated using (Jacobson 2005)

$$
\begin{aligned}
& z_{o}^{h}=\left\{\begin{array}{ccc}
z_{o}^{g} & u_{*}=0.0 & D_{h}=\frac{\kappa_{a}}{\rho_{a} c_{p, w}} \\
\max \left(0.9 z_{o}^{g}, \frac{D_{h}}{k u_{*}}\right) & u_{*} \neq 0.0 & \text { if } D_{h} \leq 0.0, D_{h}=D_{v}
\end{array}\right. \\
& z_{o}^{q}=\left\{\begin{array}{cll}
z_{o}^{g} & u_{*}=0.0 & D_{v}=2.11 \times 10^{-5}\left(\frac{T_{a}}{273.15}\right)^{1.94}\left(\frac{1013.25}{P_{a}}\right) \\
\max \left(0.9 z_{o}^{g}, \frac{D_{v}}{k u_{*}}\right) & u_{*} \neq 0.0 &
\end{array}\right.
\end{aligned}
$$

with (Louis 1979) 


$$
\begin{aligned}
& u_{*}^{2}=C_{n g}^{0} W^{2} \Gamma_{m} \quad C_{n g}^{0}=\frac{k^{2}}{\left[\ln \left(Z_{u} / z_{0}^{g}\right)\right]^{2}} \\
& \Gamma_{m}=\left\{\begin{array}{ll}
{\left[1-\frac{9.4 R_{i b}}{1+C_{m}\left|R_{i b}\right|^{1 / 2}}\right]} & R_{i b} \leq 0 \\
{\left[\frac{1}{1+4.7 R_{i b}}\right]^{2}} & R_{i b}>0
\end{array} \quad C_{m}=7.4 C_{n g}^{0} 9.4 \sqrt{\frac{Z_{u}}{z_{0}^{g}}}\right.
\end{aligned}
$$

where $R_{i b}$, the bulk Richardson number, is defined as

$$
R_{i b}=\left\{\begin{array}{cc}
0.21 & W_{a f}<0.01 \\
\frac{2 g Z_{a}\left(T_{a f}-T_{g}\right)}{\left(T_{a f}+T_{g}\right) W_{a f}^{2}} & W_{a f} \geq 0.01
\end{array}\right.
$$

and $T_{a f}(\mathrm{~K})$ and $W_{a f}(\mathrm{~m} / \mathrm{s})$ are the temperature and wind speed at the foliage/ground interface respectively (Deardorff 1978). The sensible heat exchange stability correction factor term $\left(\Gamma_{h}\right)$ in equation (2.9) that accounts for non-neutral conditions is defined as (Mascart et al. 1995)

$$
\Gamma_{h}=\left\{\begin{array}{c}
{\left[\frac{\ln \left(Z_{u} / z_{0}^{g}\right)}{\ln \left(Z_{u} / z_{0}^{h}\right)}\right]\left[1-\frac{10 R_{i b}}{1+C_{h}\left|R_{i b}\right|^{1 / 2}}\right] \quad R_{i b} \leq 0} \\
{\left[\frac{\ln \left(Z_{u} / z_{0}^{g}\right)}{\ln \left(Z_{u} / z_{0}^{h}\right)}\right]\left[\frac{1}{1+4.7 R_{i b}}\right]^{2} \quad R_{i b}>0}
\end{array} .\right.
$$

The latent heat exchange stability correction facter term, $\Gamma_{e}$, is the same as $\Gamma_{h}$, replacing $z_{o}^{h}$ with $z_{o}^{q}$ and $C_{h}$ with $C_{e} . C_{h}$ is defined as (Mascart et al. 1995) 


$$
\begin{aligned}
& C_{h}=9.4 C_{h}^{*} C_{n g}^{0}\left[\left[\frac{\ln \left(Z_{u} / z_{0}^{g}\right)}{\ln \left(Z_{u} / z_{0}^{h}\right)}\right]\right]\left(\frac{Z_{u}}{z_{0}^{h}}\right)^{p_{h}} \\
& C_{h}^{*}=3.2165+4.3431 \mu+0.536 \mu^{2}-0.0781 \mu^{3} \\
& p_{h}=0.5802-0.1571 \mu+0.0327 \mu^{2}-0.0026 \mu^{3} \\
& \mu=\ln \left(z_{0}^{g} / z_{0}^{h}\right) .
\end{aligned}
$$

$C_{e}$ is similarly calculated by substituting $z_{o}^{h}$ with $z_{o}^{q}$.

\subsection{Precipitation Flux}

In the new version of FASST, mixed precipitation is allowed. Thus, for a bare surface it is defined as

$$
P_{g}=-\left(\rho_{w} c_{p, w} \cdot\left[\text { rain fallrate }-I_{r}+D_{r}\right]+\gamma_{p} c_{p, i} \cdot\left[\text { snow fallrate }-I_{s}+D_{s}\right]\right) T_{p}
$$

with $T_{p}$ the precipitation temperature equal to the air wet-bulb temperature, $I_{r}, I_{s}$ are respectively the vegetation intercepted rain and snow $(\mathrm{m} / \mathrm{s})$, and $D_{r}, D_{s}$ are the vegetation dripped rain and snow $(\mathrm{m} / \mathrm{s})$, respectively.

\subsection{Solution}

Unlike the original version of FASST where the temperature profile was solved for before the moisture at a given time step, in the new version both profiles are iterated for simultaneously. Another change from the original version is that, since the orientation of the $\mathrm{z}$-axis is reversed, node 1 is now at the bottom of the soil instead of the top. This allows the expansion of the solution matrix if snow is present.

\section{6a Temperature}

Following the technique outlined in Celia et al. (1990) and Hansson et al. (2004) the individual terms in the left-hand side of equation (3.1) are rewritten as 


$$
\begin{gathered}
\frac{\partial c_{p} T}{\partial t}=\left[c_{p}\right]_{j, t+1 / 2}\left\{\frac{[T]_{j, t+1}^{k+1}-[T]_{j, t}}{\Delta t}\right\}=\left[c_{p}\right]_{j, t+1 / 2}\left\{\frac{\delta_{j}^{T}}{\Delta t}+\frac{[T]_{j, t+1}^{k}-[T]_{j, t}}{\Delta t}\right\} \\
-l_{\text {fus }} \rho_{i} \frac{\partial \theta_{i}}{\partial t}=-\left[l_{\text {fus }} \rho_{i}\right]_{j, t+1 / 2}\left\{\frac{\left[\theta_{i}\right]_{j, t+1}^{k+1}-\left[\theta_{i}\right]_{j, t}}{\Delta t}+\frac{\left[\theta_{i}\right]_{j, t+1}^{k+1}-\left[\theta_{i}\right]_{j, t}}{\Delta t}\right\} \\
=\left[\frac{l_{f u s}^{2} \rho_{i}}{g T} \frac{d \theta_{w}}{d \Psi}\right]_{j, t+1}^{k}\left\{\frac{\delta_{j}^{T}}{\Delta t}\right\}-\left[l_{f u s} \rho_{i}\right]_{j, t+1 / 2}\left\{\frac{\left[\theta_{i}\right]_{j, t+1}^{k+1}-\left[\theta_{i}\right]_{j, t}}{\Delta t}\right\} \\
l_{w} \rho_{w} \frac{\partial \theta_{v}}{\partial t}=\left[l_{w} \rho_{w}\right]_{j, t+1 / 2}\left\{\frac{\left[\theta_{v}\right]_{j, t+1}^{k+1}-\left[\theta_{v}\right]_{j, t}}{\Delta t}+\frac{\left[\theta_{v}\right]_{j, t+1}^{k+1}-\left[\theta_{v}\right]_{j, t}}{\Delta t}\right\} \\
=\left[l_{w} \rho_{w}\right]_{j, t+1 / 2}\left\{\left[\frac{d \theta_{v}}{d T}\right]_{j, t+1}^{k}\left[\frac{\delta_{j}^{T}}{\Delta t}\right]^{k}\left[\frac{\left[\theta_{v}\right]_{j, t+1}^{k+1}-\left[\theta_{v}\right]_{j, t}}{\Delta t}\right\}\right.
\end{gathered}
$$

where $\delta_{j}^{T}=T_{j, t+1}^{k+1}-T_{j, t+1}^{k}$ and the subscript " $j$ " is depth and the superscript " $k$ " is the iteration level. The right-hand side of equation (3.1) for the interior nodes becomes

$$
\begin{aligned}
& \frac{\partial}{\partial z}\left(\kappa \frac{\partial T}{\partial z}-v_{w} c_{p, w} T-v_{v} c_{p, v}(T-273.15)-l_{w} \rho_{w} v_{v}\right)+c_{p, w} \rho_{w}(\text { sources -losses }) T \\
& =\frac{1}{\Delta z_{j}}\left\{q_{j+1 / 2, t+1 / 2}-q_{j-1 / 2, t+1 / 2}\right\}+\left[\rho_{w}\right]_{j, t+1 / 2}(\text { sources -losses })_{j, t+1 / 2}\left(\frac{\delta_{j}^{T}+T_{j, t+1}^{k}+T_{j, t}}{2}\right) .
\end{aligned}
$$

Expanding only the $q_{j+1 / 2, t+1 / 2}$ term since the $q_{j-1 / 2, t+1 / 2}$ term is similar

$$
q_{j+1 / 2, t+1 / 2}=\frac{1}{2}\left\{\begin{array}{l}
\kappa_{j+1 / 2, t+1}^{k}\left(\frac{\delta_{j+1}^{T}-\delta_{j}^{T}}{z_{j+1}-z_{j}}+\frac{T_{j+1, t+1}^{k}-T_{j, t+1}^{k}}{z_{j+1}-z_{j}}\right)+\kappa_{j+1 / 2, t}\left(\frac{T_{j+1, t}-T_{j, t}}{z_{j+1}-z_{j}}\right) \\
-\left[v_{w} c_{p, w}+v_{v} c_{p, v}\right]_{j+1 / 2, t+1}^{k}\left(\frac{\delta_{j+1}^{T}+\delta_{j}^{T}}{2}+\frac{T_{j+1, t+1}^{k}+T_{j, t+1}^{k}}{2}-273.15\right.
\end{array}\right) .
$$


For the node at the bottom of the soil column $(j=1), q_{j-1 / 2, t+1 / 2}$ is

$$
q_{j-1 / 2, t+1 / 2}=\frac{1}{2}\left\{\begin{array}{l}
2(0.075)-\left[v_{w} c_{p, w}+v_{v} c_{p, v}\right]_{j, t+1}^{k}\left(\frac{\delta_{j}^{T}}{2}+\frac{T_{j, t+1}^{k}}{2}-273.15\right) \\
-\left[v_{w} c_{p, w}+v_{v} c_{p, v}\right]_{j, t}\left(\frac{T_{j, t}}{2}-273.15\right)-\left[l_{w} \rho_{w} v_{v}\right]_{j, t+1}^{k}-\left[l_{w} \rho_{w} v_{v}\right]_{j, t}
\end{array}\right\},
$$

while for the surface node $(j=$ nnodes $)$ without vegetation it is

$$
q_{j+1 / 2, t+1 / 2}=\frac{1}{2}\left\{\begin{array}{l}
{\left[I_{s}^{\downarrow}\left(1-\alpha_{g}\right)+\varepsilon_{g} I_{i r}^{\downarrow}-\varepsilon_{g} \sigma T_{j}^{4}-P_{g}+H_{g}+L_{g}\right]_{j, t+1}^{k}} \\
+\left[I_{s}^{\downarrow}\left(1-\alpha_{g}\right)+\varepsilon_{g} I_{i r}^{\downarrow}-\varepsilon_{g} \sigma T_{j}^{4}-P_{g}+H_{g}+L_{g}\right]_{j, t} \\
-\left[v_{w} c_{p, w}+v_{v} c_{p, v}\right]_{j, t+1}^{k}\left(\frac{\delta_{j}^{T}}{2}+\frac{T_{j, t+1}^{k}}{2}-273.15\right) \\
-\left[v_{w} c_{p, w}+v_{v} c_{p, v}\right]_{j, t}\left(\frac{T_{j, t}}{2}-273.15\right)-\left[l_{w} \rho_{w} v_{v}\right]_{j, t+1}^{k}-\left[l_{w} \rho_{w} v_{v}\right]_{j, t}
\end{array}\right\} .
$$

If vegetation is present, then equation (3.20) for the vegetation $(j=$ nnodes $+1)$ and surface $(j=$ nnodes $)$ nodes is written respectively as 


$$
\begin{aligned}
& q_{j+1 / 2, t+1 / 2}-q_{j-1 / 2, t+1 / 2}=\frac{1}{2}\left\{\begin{array}{l}
{\left[\sigma_{f}\left[I_{s}^{\downarrow}\left(1-\alpha_{f}\right)+\varepsilon_{f} I_{i r}^{\downarrow}-\varepsilon_{f} \sigma T_{f}^{4}-P_{f}\right]+\frac{\sigma_{f} \varepsilon_{f} \varepsilon_{g} \sigma}{\varepsilon_{1}}\left(T_{j-1}^{4}-T_{j}^{4}\right)+H_{f}+L_{f}\right]_{j, t+1}^{k}} \\
\left.+\sigma_{f}\left[I_{s}^{\downarrow}\left(1-\alpha_{f}\right)+\varepsilon_{f} I_{i r}^{\downarrow}-\varepsilon_{f} \sigma T_{f}^{4}-P_{f}\right]+\frac{\sigma_{f} \varepsilon_{f} \varepsilon_{g} \sigma}{\varepsilon_{1}}\left(T_{j-1}^{4}-T_{j}^{4}\right)+H_{f}+L_{f}\right]_{j, t} \\
-\left[\sigma_{f} \kappa\right]_{j-1 / 2, t+1}^{k}\left(\frac{\delta_{j}^{T}-\delta_{j-1}^{T}}{z_{j}-z_{j-1}}+\frac{T_{j, t+1}^{k}-T_{j-1, t+1}^{k}}{z_{j}-z_{j-1}}\right)-\left[\sigma_{f} \kappa\right]_{j-1 / 2, t}\left(\frac{T_{j, t}-T_{j-1, t}}{z_{j}-z_{j-1}}\right)
\end{array}\right\} \\
& \left(\left[\left(1-\sigma_{f}\right)\left[I_{s}^{\downarrow}\left(1-\alpha_{g}\right)+\varepsilon_{g} I_{i r}^{\downarrow}-\varepsilon_{g} \sigma T_{g}^{4}\right]-P_{g}-\frac{\sigma_{f} \varepsilon_{f} \varepsilon_{g} \sigma}{\varepsilon_{1}}\left(T_{j}^{4}-T_{j+1}^{4}\right)+H_{g}+L_{g}\right]_{j, t+1}^{k}\right) \\
& +\left[\left(1-\sigma_{f}\right)\left[I_{s}^{\downarrow}\left(1-\alpha_{g}\right)+\varepsilon_{g} I_{i r}^{\downarrow}-\varepsilon_{g} \sigma T_{g}^{4}\right]-P_{g}-\frac{\sigma_{f} \varepsilon_{f} \varepsilon_{g} \sigma}{\varepsilon_{1}}\left(T_{j}^{4}-T_{j+1}^{4}\right)+H_{g}+L_{g}\right]_{j, t} \\
& q_{j+1 / 2, t+1 / 2}-q_{j-1 / 2, t+1 / 2}=\frac{1}{2}\left\{+\left[\sigma_{f} \kappa\right]_{j+1 / 2, t+1}^{k}\left(\frac{\delta_{j+1}^{T}-\delta_{j}^{T}}{z_{j+1}-z_{j}}+\frac{T_{j+1, t+1}^{k}-T_{j, t+1}^{k}}{z_{j+1}-z_{j}}\right)+\left[\sigma_{f} \kappa\right]_{j+1 / 2, t}\left(\frac{T_{j+1, t}-T_{j, t}}{z_{j+1}-z_{j}}\right)\right. \\
& -\left[v_{w} c_{p, w}+v_{v} c_{p, v}\right]_{j, t+1}^{k}\left(\frac{\delta_{j}^{T}}{2}+\frac{T_{j, t+1}^{k}}{2}-273.15\right)-\left[v_{w} c_{p, w}+v_{v} c_{p, v}\right]_{j, t}\left(\frac{T_{j, t}}{2}-273.15\right) \\
& -\left[l_{w} \rho_{w} v_{v}\right]_{j, t+1}^{k}-\left[l_{w} \rho_{w} v_{v}\right]_{j, t}
\end{aligned}
$$

Substituting equations (3.19)-(3.24) into equation (3.1), assuming (2.16) is still valid and rearranging so that all $\delta^{T}$ terms are on the left-hand side, the final temperature equation is

$$
A_{j}^{T} \delta_{j-1}^{T}+B_{j}^{T} \delta_{j}^{T}+C_{j}^{T} \delta_{j+1}^{T}=D_{j}^{T}
$$

A Newton-Raphson technique is used to solve the system of linear equations as with the original version of FASST.

\section{6b Moisture}

Similar to the solution technique for the temperature equation, I follow the technique outlined in Celia et al. (1990). Equation (3.7) is thus 


$$
\begin{aligned}
\frac{\partial \theta}{\partial t} & =-\frac{\partial}{\partial z}\{v\}+\text { sources }- \text { sinks } \\
& =-\frac{1}{\Delta z_{j}}\left\{v_{j+1 / 2, t+1 / 2}-v_{j-1 / 2, t+1 / 2}\right\}+(\text { sources }- \text { sinks })_{j, t+1 / 2}
\end{aligned}
$$

where $\frac{\partial \theta}{\partial t}=\frac{\partial \theta_{w}}{\partial t}+\frac{\partial \theta_{v}}{\partial t}+\frac{\rho_{i}}{\rho_{w}} \frac{\partial \theta_{i}}{\partial t}, v=v_{w}+v_{v}$ and $v_{j \pm 1 / 2, t+1 / 2}=\frac{1}{2}\left(v_{j \pm 1 / 2, t+1}+v_{j \pm 1 / 2, t}\right)$.

At the surface, $v_{j+1 / 2, t}=q_{t o p}$ while at the bottom, $v_{j-1 / 2, t}=q_{b o t}$, both of which are given in equation (2.6). Expanding the left-hand side of equation (3.26)

$$
\begin{aligned}
\frac{\partial\left[\theta_{w}\right]_{j}}{\partial t} & =\frac{\left[\theta_{w}\right]_{j, t+1}^{k+1}-\left[\theta_{w}\right]_{j, t}}{\Delta t}=\frac{\left[\theta_{w}\right]_{j, t+1}^{k+1}-\left[\theta_{w}\right]_{j, t+1}^{k}+\left[\theta_{w}\right]_{j, t+1}^{k}-\left[\theta_{w}\right]_{j, t}}{\Delta t} \\
& =\left.\frac{d \theta_{w}}{d \Psi}\right|_{j, t+1} ^{k} \frac{\Psi_{j, t+1}^{k+1}-\Psi_{j, t+1}^{k}}{\Delta t}+\frac{\left[\theta_{w}\right]_{j, t+1}^{k}-\left[\theta_{w}\right]_{j, t}}{\Delta t} \\
& =\left.\frac{d \theta_{w}}{d \Psi}\right|_{j, t+1} ^{k} \frac{\delta_{j}^{\Psi}}{\Delta t}+\frac{\left[\theta_{w}\right]_{j, t+1}^{k}-\left[\theta_{w}\right]_{j, t}}{\Delta t} \\
\frac{\partial \theta_{v}}{\partial t}+\frac{\rho_{i}}{\rho_{w}} \frac{\partial \theta_{i}}{\partial t} & =\frac{\left[\theta_{v}\right]_{j, t+1}^{k}-\left[\theta_{v}\right]_{j, t}}{\Delta t}+\left[\frac{\rho_{i}}{\rho_{w}}\right]_{j, t+1 / 2} \frac{\left[\theta_{i}\right]_{j, t+1}^{k}-\left[\theta_{i}\right]_{j, t}}{\Delta t}
\end{aligned}
$$

where " $k$ " is the iteration level and $\delta_{j}^{\Psi}=\Psi_{j, t+1}^{k+1}-\Psi_{j, t+1}^{k}$. The $\left[v_{w}\right]_{j+1 / 2, t+1 / 2}$ term in the right-hand side of equation (3.26) becomes

$$
\left[v_{w}\right]_{j+1 / 2, t+1 / 2}=-\frac{1}{2}\left\{\begin{array}{l}
{\left[K_{l h}\right]_{j+1 / 2, t+1}^{k}\left(\frac{\delta_{j+1}^{\Psi}-\delta_{j}^{\Psi}}{Z_{j+1}-Z_{j}}+\frac{\Psi_{j+1, t+1}^{k}-\Psi_{j, t+1}^{k}}{Z_{j+1}-Z_{j}}+1\right)} \\
+\left[K_{l T}\right]_{j+1 / 2, t+1}^{k}\left(\frac{T_{j+1, t+1}^{k}-T_{j, t+1}^{k}}{Z_{j+1}-Z_{j}}\right) \\
+\left[\frac{\Psi_{j+1, t}-\Psi_{j, t}}{Z_{j+1}-Z_{j}}+1\right)+\left[K_{l T}\right]_{j+1 / 2, t}\left(\frac{T_{j+1, t}-T_{j, t}}{Z_{j+1}-Z_{j}}\right)
\end{array}\right\} .
$$

Except for the “+ 1 " terms in equation (3.28), the expression for $\left[v_{v}\right]_{j+1 / 2, t+1 / 2}$ is the same. The same principle is applied to the $[v]_{j-1 / 2, t+1 / 2}$ term in equation (3.26). Substituting equations (3.27) and (3.28) into equation (3.26) and rearranging so that all $\delta^{\Psi}$ terms are on the left-hand side, the final moisture equation is 


$$
A_{j}^{\Psi} \delta_{j-1}^{\Psi}+B_{j}^{\Psi} \delta_{j}^{\Psi}+C_{j}^{\Psi} \delta_{j+1}^{\Psi}=D_{j}^{\Psi}
$$

As with the original version of FASST, a Newton-Raphson technique is used to solve the system of linear equations. 


\section{References}

Balick, L.R., R.K. Scoggins, and L.E. Link (1981) Inclusion of a simple vegetation layer in terrain temperature models for thermal IR signature prediction. IEEE Transaction on Geoscience and Remote Sensing, GE-19(3): 143-152.

Celia, M.A., and E.T. Bouloutas (1990) A general mass-conservative numerical solution for the unsaturated flow equation. Water Resources Research, 26(7): 1483-1496.

Deardorff, J.W. (1978) Efficient prediction of ground surface temperature and moisture, with inclusion of a layer of vegetation. Journal of Geophysical Research, 83(C4): 1889-1903.

Engineering ToolBox (2005), http://www.engineeringtoolbox.com.

Farouki, O.T. (1981) Thermal Properties of Soils. US Army Cold Regions Research and Engineering Laboratory, Hanover, New Hampshire, Monograph 81-1.

Fayer, M.J. (2000) UNSAT-H Version 3.0: Unsaturated Soil Water and Heat Flow Model, Theory, User Manual and Examples, PNNL-13249.

Frankenstein, S., and G. Koenig (2004a) Fast All Season Soil STrength (FASST) Model, US Army Engineer Research and Development Center, Cold Regions Research and Engineering Laboratory, Hanover, New Hampshire, ERDC/CRREL Special Report SR-04-1. http://www.crrel.usace.army.mil/techpub/CRREL_Reports/ reports/SR04-1.pdf

Frankenstein, S., and G. Koenig (2004b) Vegetation Modules in FASST, US Army Engineer Research and Development Center, Cold Regions Research and Engineering Laboratory, Hanover, New Hampshire, ERDC/CRREL Technical Report TR-04-25. http://www.crrel.usace.army.mil/techpub/CRREL_Reports/ reports/TR04-25.pdf

Hansson, K., J. Šimůnek, M. Mizoguchi, L.-C. Lundin, and M. Th. van Genuchten (2004) Water flow and heat transport in frozen soil: Numerical solution and freeze-thaw applications. Vadose Zone Journal, 3: 693-704.

Hillel, D. (1998) Environmental Soil Physics, San Diego: Academic Press.

Hornbeck, R.W. (1975) Numerical Methods, New Jersey: Prentice-Hall.

Ierardi, J. (1999) http://users.wpi.edu/ ieardi/PDF.

Jacobson, M.Z. (2005) Presentation Slides, Chapters 8, 2 of Fundamentals of Atmospheric Modeling, $2^{\text {nd }}$ Edition, Department of Civil \& Environmental Engineering, Stanford University, www.stanford.edu/group/efmh/ FAMbook2dEd/Chap8FAMII.ppt.

Jordan, R. (1991) A One-Dimensional Temperature Model for a Snow Cover: Technical Documentation of SNTHERM.89. US Army Cold Regions Research and Engineering Laboratory, Hanover, New Hampshire, Special Report 91-16. 
Koenig, G.G. (1994) Smart Weapons Operability Enhancement (SWOE) Joint Test and Evaluation (JT \& E) Program Final Report. Dr. James P. Welch, Joint Test Director, SWOE JT \& E, SWOE Report 94-10, Annex D.

Louis, J.-F. (1979) A parametric model of vertical eddy fluxes in the atmosphere. Boundary-Layer Meteorology, 17(2): 187-202.

Mascart, P., J. Noilhan, and H. Giordani (1995) A modified parameterization of fluxprofile relationships in the surface layer using different roughness length values for heat and momentum. Boundary-Layer Meteorology, 72(4): 331-344.

Moore, C.J., and G. Fisch (1986) Estimating heat storage in Amazonian tropical forest. Agricultural and Forest Meteorology, 38: 147-169.

Nassar, I.N., and R. Horton (1989) Water transport in unsaturated nonisothermal salty soil: II. Theoretical development. Soil Science Society of America Journal, 53: 1330-1337.

Niu, G.-Y., and Z.-L. Yang (2006) Effects of frozen soil on snowmelt runoff and soil water storage at a continental scale. Journal of Hydrometeorology, 7(5): 937-952.

Noborio, K., K.J. McInnes, and J.L. Heilman (1996) Two-dimensional model for water, heat, and solute transport in furrow-irrigated soil: II. Field evaluation. Soil Science Society of America Journal, 60: 1010-1021.

van Genuchten, M. Th. (1980) A closed-form equation for predicting the hydraulic conductivity of unsaturated soils. Soil Science Society of America Journal, V. 44, p. 892-898. 


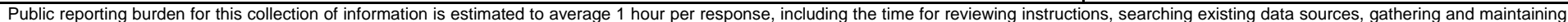

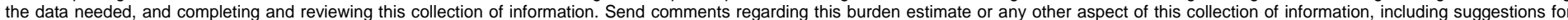

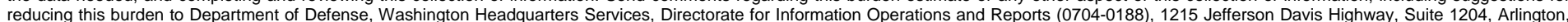

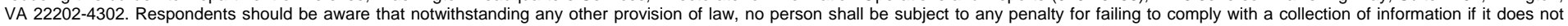
display a currently valid OMB control number. PLEASE DO NOT RETURN YOUR FORM TO THE ABOVE ADDRESS.

\begin{tabular}{l|l}
$\begin{array}{l}\text { 1. REPORT DATE (DD-MM- } Y Y Y Y) \\
\text { April } 2008\end{array}$ & $\begin{array}{l}\text { 2. REPORT TYPE } \\
\text { Technical Report }\end{array}$ \\
\hline
\end{tabular}

\section{TITLE AND SUBTITLE}

FASST Soil Moisture, Soil Temperature: Original Versus New

3. DATES COVERED (From - To)

5a. CONTRACT NUMBER

5b. GRANT NUMBER

5c. PROGRAM ELEMENT NUMBER

6. AUTHOR(S)

Susan Frankenstein

7. PERFORMING ORGANIZATION NAME(S) AND ADDRESS(ES)

US Army Engineer Research and Development Center

Cold Regions Research and Engineering Laboratory

72 Lyme Road

Hanover, New Hampshire 03755-1290

9. SPONSORING I MONITORING AGENCY NAME(S) AND ADDRESS(ES) 5d. PROJECT NUMBER

5e. TASK NUMBER

5f. WORK UNIT NUMBER

8. PERFORMING ORGANIZATION REPORT NUMBER

ERDC/CRREL TR-08-7

10. SPONSOR/MONITOR'S ACRONYM(S)

11. SPONSOR/MONITOR'S REPORT NUMBER(S)

\section{DISTRIBUTION / AVAILABILITY STATEMENT}

Approved for public release; distribution is unlimited.

Available from NTIS, Springfield, Virginia 22161.

13. SUPPLEMENTARY NOTES

\section{ABSTRACT}

This paper discusses only the differences between the original version of FASST (Frankenstein and Koenig 2004a, 2004b) and the new version. This report is intended as a supplement to the original model documentation. In its original incarnation, energy and mass transport associated with water vapor in the soil matrix were ignored. The author added these so that model usage could be expanded to include biological investigations yet still retain its initial focus of soil strength, and sensor performance inputs. Also ignored in the original version was water transport due to soil temperature gradients. In determining the new soil temperatures and moistures, the original model first achieved convergence in the temperature profile followed by the moisture profile at a given time step. The new version of FASST solves both of these sets of equations simultaneously. No changes have been made to the equations describing the canopy physical state except to allow for mixed precipitation.

\section{SUBJECT TERMS}

FASST, Model, Moisture, Soil, Temperature, Vegetation 16. SECURITY CLASSIFICATION OF:

\begin{tabular}{|c|c|r|}
\hline a. REPORT & b. ABSTRACT & c. THIS PAGE \\
$\mathrm{U}$ & $\mathrm{U}$ & $\mathrm{U}$ \\
\hline
\end{tabular}

\begin{tabular}{|c|c|}
$\begin{array}{l}\text { 17. LIMITATION } \\
\text { OF ABSTRACT }\end{array}$ & $\begin{array}{c}\text { 18. NUMBER } \\
\text { OF PAGES }\end{array}$ \\
$\mathrm{U}$ & 38 \\
\hline
\end{tabular}

19a. NAME OF RESPONSIBLE PERSON

19b. TELEPHONE NUMBER (include area code) 